\title{
Modelling and simulation of Just-In-Time flexible systems
}

\author{
K RAVI RAJU ${ }^{1}$, K RAMA BHUPAL REDDY $^{1}$ and \\ O V KRISHNAIAH CHETTY ${ }^{2}$
}

\author{
'Department of Mechanical Engineering, Indian Institute of Technology, \\ Hauz Khas, New Delhi 110016, India \\ ${ }^{2}$ Department of Mechanical Engineering, Indian Institute of Technology, \\ Madras 600 036, India \\ e-mail: [raviraju,krbreddy]@mech.iitd.ernet.in; ovk@acer.iitm.ernet.in
}

\begin{abstract}
The increasing worldwide competition requires economical manufacture, high quality and short delivery time. The Just-In-Time (JIT) philosophy of manufacturing is increasingly being considered by manufacturing organizations, as a response to the increased pressure to supply high quality products with short delivery times and at low cost. A very simple shop floor control system that was developed by Toyota in the 1970s specifically for their Just-In-Time assembly plant, has received considerable attention in the Western World, and is known as the 'kanban' system (literally translated as 'card' system). Japan's success has prompted many scholars and practitioners, to turn their attention to Japanese management practices. This article is to address the modelling, simulation and implementation issues of Just-In-Time in flexible manufacturing environments. Priority nets are used for modelling and analysis of the kanban system. A large number of simulation runs are conducted/presented to probe the behaviour of the system, with respect to different parameter changes.
\end{abstract}

Keywords. Just-In-Time; flexible manufacturing systems; kanban.

\section{Introduction}

Just-In-Time (JIT) is considered to be one of the major factors contributing to the success of Japanese industries (Sugimori et al 1977; Monden 1981, 1983; Schonberger 1982). The JIT approach to production was originated by Toyota in 1970s in their car assembly plants in Japan, and has found most success in repetitive manufacturing environments. The JIT philosophy has attracted increased attention from researchers who have tried to explain JIT implementation successes and failures outside Japan (Narendar et al 1995). The objectives of the JIT system are to maximize the velocity of material flow through the plant, by arranging materials to arrive at each stage of manufacture just in time, to be processed and move on to the next stage. JIT manufacture is a well-proven manufacturing management philosophy which aims at eliminating the Work-In-Process (WIP) and optimizes material 
delivery timings. Traditionally it is applied in the mass manufacturing environment. In recent years, it also being implemented in flexible manufacturing environment. A survey by Kim \& Schniederjans (1990) which includes 450 US manufacturing firms emphasizes that a computer-integrated JIT system is more productive, cost efficient and highly effective in producing a quality product than a JIT or CIM system alone. To date, there is a lot of reported research in the areas of JIT and flexible manufacturing individually. However, there is no detailed investigation of implementing JIT in flexible manufacturing environments. Hence, to realize the full benefits of JIT in flexible manufacturing, many implementation issues have to be investigated.

Though, JIT offers many advantages such as WIP reduction, increased flexibility and quality, reduced space requirements etc., its implementation is not always a success. Indeed, on the one hand it necessitates a specific consumption of finished products that is regular enough, while on the other, it necessitates major changes in manufacturing process such as reducing setup times, increasing reliability, improving product quality and reducing customer response time (Schonberger 1982; White 1993). Thus these problems justify the interest in methods to evaluate the performance of these systems.

Kanban system is the backbone of JT philosophy. The philosophy behind the kanban approach is, the work should never be pushed on to the next work centre until that work centre is ready for it. This utilizes cards to authorize production and move material between work centres. In the literature, kanban systems have been studied using a variety of methods. Some researchers have analyzed JIT systems using mathematical programming (Bitran \& Chang 1987; Mitra \& Mitrani 1988; Wang \& Wang 1991). Simulation is frequently used to evaluate JIT systems (Huang et al 1983; Schroer et al 1985; Lulu \& Black 1987). System dynamics models are also used to study the kanban systems (Gupta \& Gupta 1989). Mascolo et al (1991) have demonstrated the suitability of Petri Nets for unified modelling of kanban systems.

The objective of this paper is to establish priority nets (PRNs) as powerful and flexible tools for modelling and analysis of JIT manufacturing systems. It also details the differences between the implementation issues of conventional manufacturing systems (CMSs) and FMSs, and addresses some of the issues with petri net-based simulation.

\section{JIT in flexible manufacturing environment}

The success of JT mainly depends on the nature of manufacturing environment. It is found to be more suitable for a repetitive manufacturing environment, where products are regularly ordered. The suitability of JIT for manufacturing environment is summarized in figure 1 (Voss \& Harrison 1987). Systems with mid volume and mid variety (flexible manufacturing environment) almost certainly have part or all of their manufacturing suitable for JIT, those at the top left and bottom right are suitable for selected applications.

The second criterion for determining the suitability of JIT is based on the complexity of product structure and process routing, figure 2 (Voss \& Harrison 1987). The more complex they are, the less suitable JIT is for planning and controlling production. 


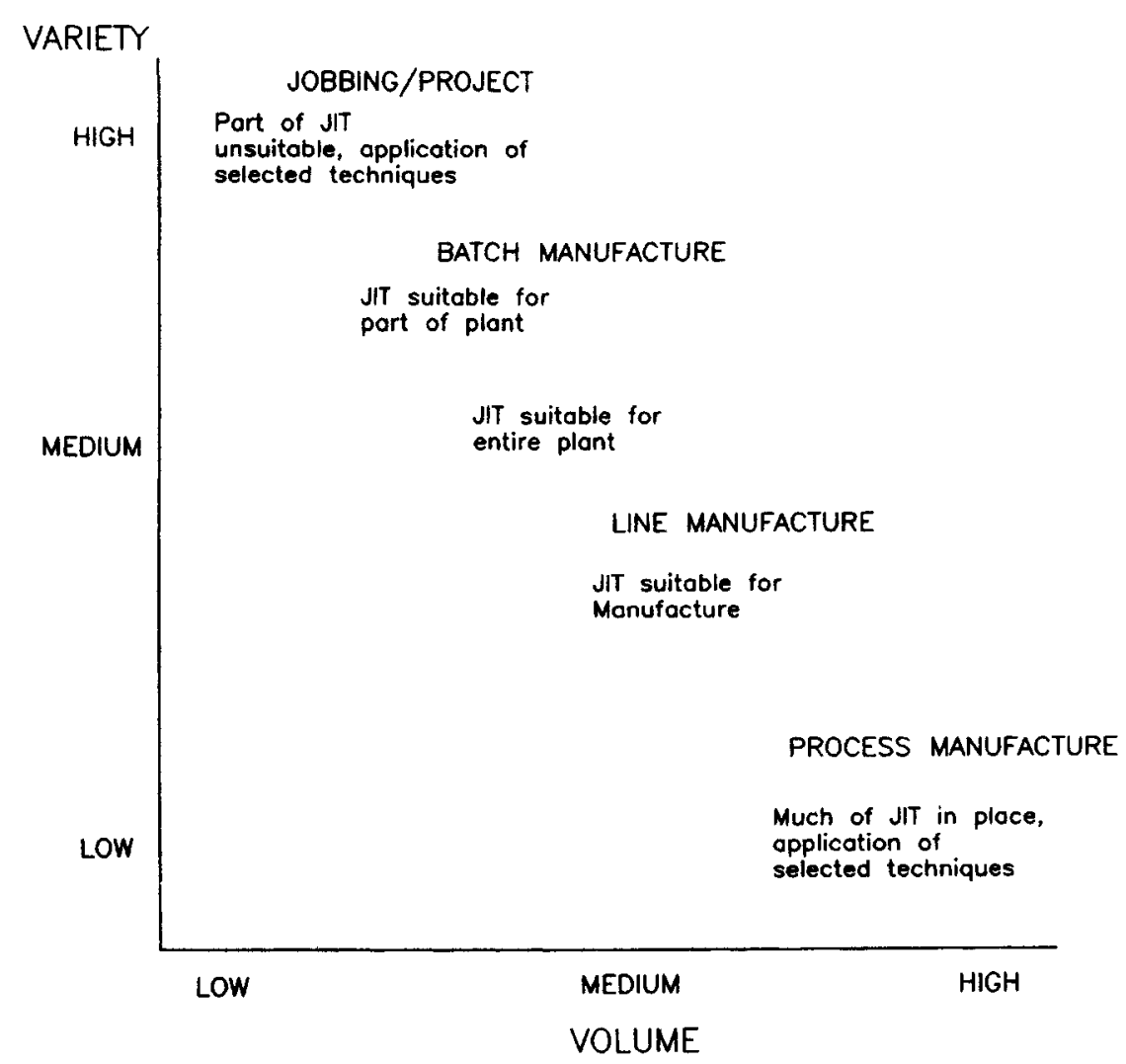

Figure 1. JIT and the manufacturing environment (Voss \& Harrison 1987).

\section{$2.1 \quad J I T$ in FMSs}

JIT systems require production processes which can economically produce small runs of products. This flexibility is generally required to support the JIT concept. Economical small production runs are achieved by reducing the equipment setup time which is the fixed cost component associated with each production run. With the advent of FMS this requirement has become a reality. FMSs have the ability to produce a wide range of parts quickly in small lots, and thus fit well into the JIT approach. In addition, it can be stated that without some form of FMS or flexible manufacturing facility, it is difficult to implement JIT effectively within a batch manufacturing environment.

\subsection{JIT in flexible assembly systems}

Flexibility in assembly is a fast-growing prerequisite imposed by present day industry, due to the ever-increasing variety of models, and to quickly respond to market changes. The advent of programmable industrial robots spurred the development of FASs. JIT is successfully implemented in many FASs. For example, an FAS is installed at International Computers Ltd. (ICL, England) integrating assembly, testing and philosophy. This system caters to a variety of ICL computers and computer products. JIT is implemented with the 


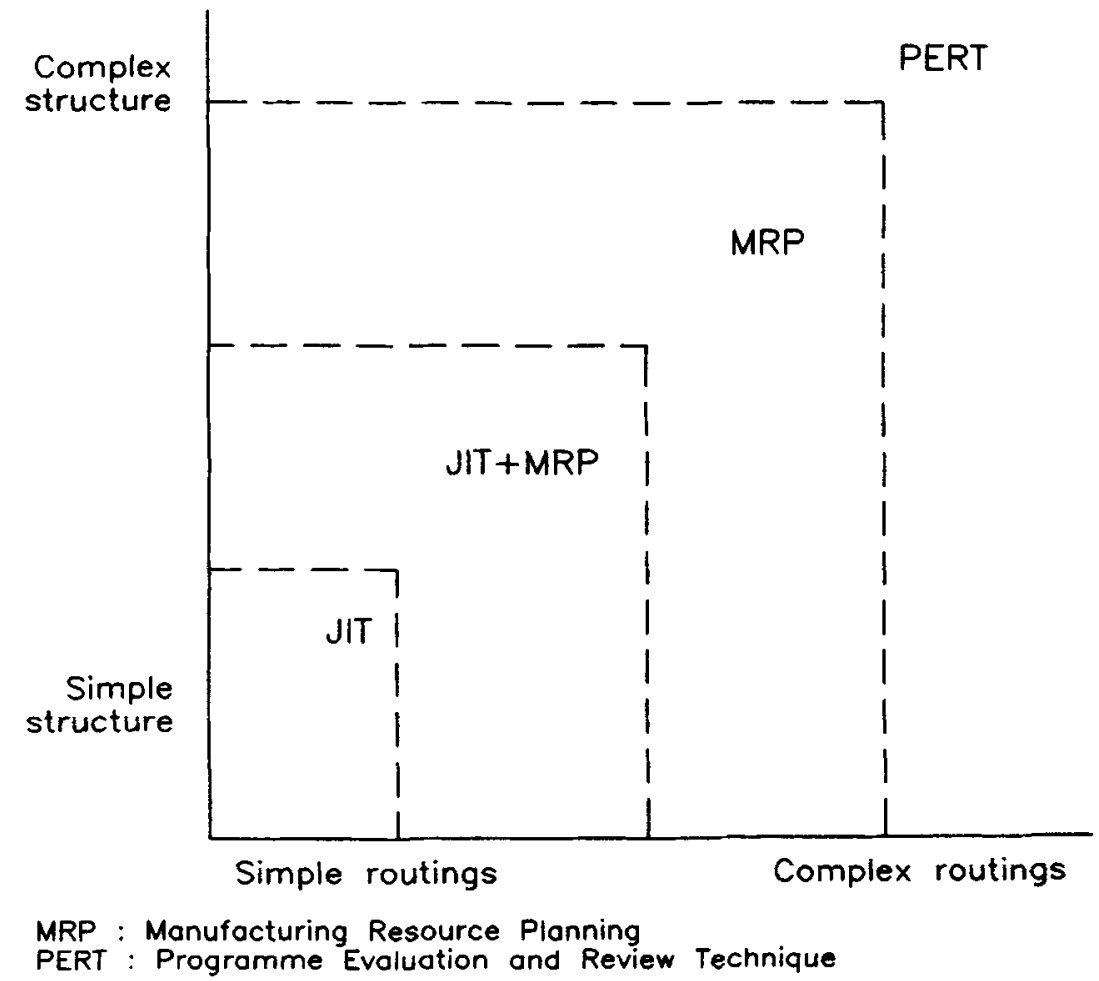

Figure 2. Suitability of JIT for controlling production (Voss \& Harrison 1987).

help of central software and coded pallets (Talavase \& Hannam 1988). Pye Telecommunications Ltd., successfully implemented FAS with JIT, with a $96 \%$ reduction in lead time and WIP (Wilson 1986).

\subsection{JIT in job shop environment}

JIT approach is traditionally thought to be not suitable for small industries operating as job shops. However, in a publication (Gravel \& Price 1988), it is reported that Kanban method can be successfully adapted to the job shop environment. This is tested in a firm, manufacturing high quality outdoor clothing and the results of the pilot run are found to be encouraging. However, the authors felt that some of the modelling and practical issues need to be resolved before successful implementation.

\section{JIT implementation issues}

The implementation issues of JIT in FMSs are different from those in CMSs, since (i) the configurations, (ii) the main criteria in each of the cases are different. In the environment of FMS/FAS, the multi-functional workers are replaced by robots, conventional machines are replaced by CNC machining centres and moving carts by AGVs. In CMSs, the main criteria is to maintain the lowest possible inventories even though the utilization of the some of the machines is reduced. But in FMSs, the utilization of machining centres must 
be high to justify this investment. Therefore, for implementing JIT in FMSs a balance has to be achieved between inventory levels and utilization levels. Also the degree of automation has to be kept low to reduce the production cost. Masuyama (1986), has discussed some of the implementation issues in FMS environment.

The prominent issues for the successful implementation of JIT in either CMSs or FMSs are: (1) reduction in setup times, (2) reduction in conveyance times between machines, and (3) number of kanbans and kanban sizes. However, there are additional issues to be addressed in the context of FMSs due to the fact that (a) multiple-part types are processed simultaneously, and (b) the systems have to respond to the changes in part types and volumes. The additional issues are:

(1) kanban related issues in multi product environment,

(2) part routings and layout, and

(3) AGV related issues.

\subsection{Reduction of setup times}

Monden (1981, 1983) separates setup times in CMSs into (i) internal (actions that require the machine to be stopped) and (ii) external (actions that can take place when the machine is running) setup times. Efforts are then made to convert maximum possible amount of internal setup time to external in order to reduce the overall setup time. Internal setup time in FMSs is almost negligible due to flexibility of CNC machining centres with automated tool-handling facilities.

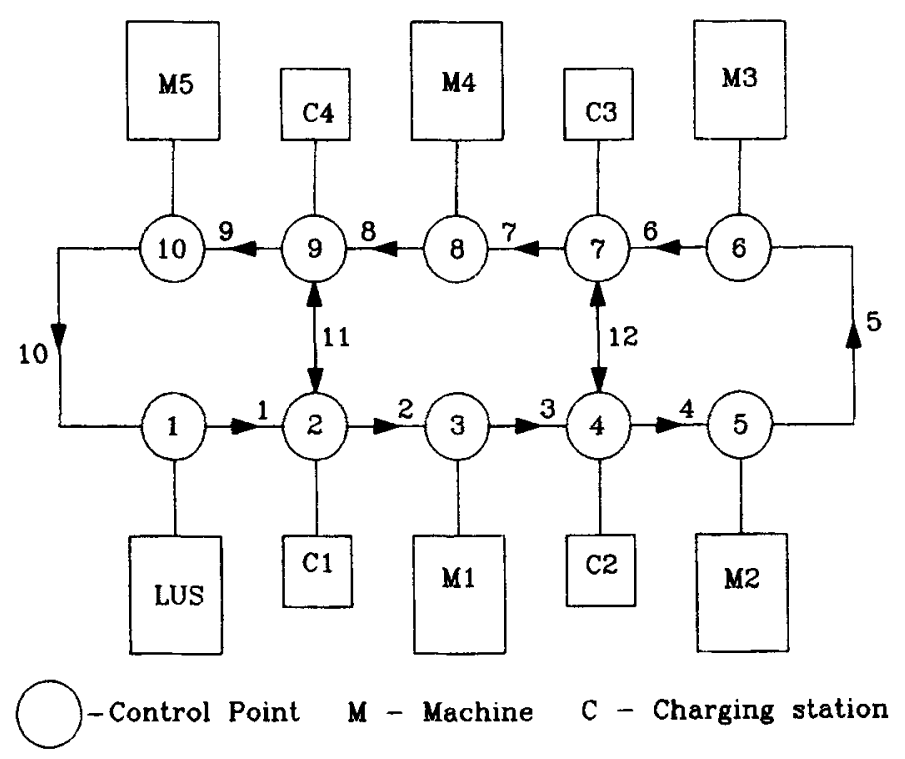

Figure 3. Layout of the system. 
Table 1. Part routings and processing times.

\begin{tabular}{lll}
\hline Part type & \multicolumn{1}{c}{ Routing } & \multicolumn{1}{c}{ Processing times } \\
\hline PR1 & LUS-M1-M2/M3-M4-LUS & $30-150-240 / 290-230-30$ \\
PR2 & LUS-M4/M5-M1-M2/M3/LUS & $30-205 / 250-170-205 / 290-30$ \\
PR3 & LUS-M2/M3-M5-M1/M4-LUS & $30-220 / 240-275-290 / 240-30$ \\
\hline
\end{tabular}

\subsection{Reduction of conveyance times}

Conveyance times in CMSs are reduced by belt conveyors, chutes or fork lifts. As these types are limited in flexibility for transferring parts/materials, they cannot be used in the environment of FMSs as asynchronous flow of material is mandatory. Owing to this AGVs are generally preferred in FMSs.

\subsection{Reduction of number of kanbans and lot sizes}

The inventory in a system is tightly controlled with the help of kanbans. A kanban system lowers WIP levels by decreasing either the number of kanbans or the kanban size (lot size). Reducing production lead time is very crucial for the operation of JIT systems with varying demand, without high levels of either safety stocks or stock-outs. Recent literature indicates that there is a significant relation between batch size and production lead time. Hence, determination of the optimum number of kanbans and lot sizes is very important in both CMSs and FMSs.

\subsection{Kanban-related issues in FMS environment}

The following issues are important in the context of FMSs.

3.4a Pallet as a container: In CMSs, special containers are used for each part type. In FMSs, parts are generally loaded onto pallets and routed through the machines. Pallets form the interface between the workpiece and the machines. Thus the pallets act as containers in this case. These pallets are generally coded and contain necessary information.

FMSs are capable of processing families composed of a large number of part types. Two different kinds of families (closed and open family) can be taken into account. In the first case, the mix of the part types is predetermined and the system is setup for long time production of some part types. Under these conditions, dedicated pallets with special fixtures are used for speeding up loading and unloading operations. When open families are considered, the system must quickly be able to fit every requirement. In this case adaptable pallets equipped with all-purpose clamping devices are more suitable. These pallets can

Table 2. AGV travel times.

\begin{tabular}{ll}
\hline Segment number & 123456789101112 \\
\hline Travel time (s) & 101010102010101010201515
\end{tabular}




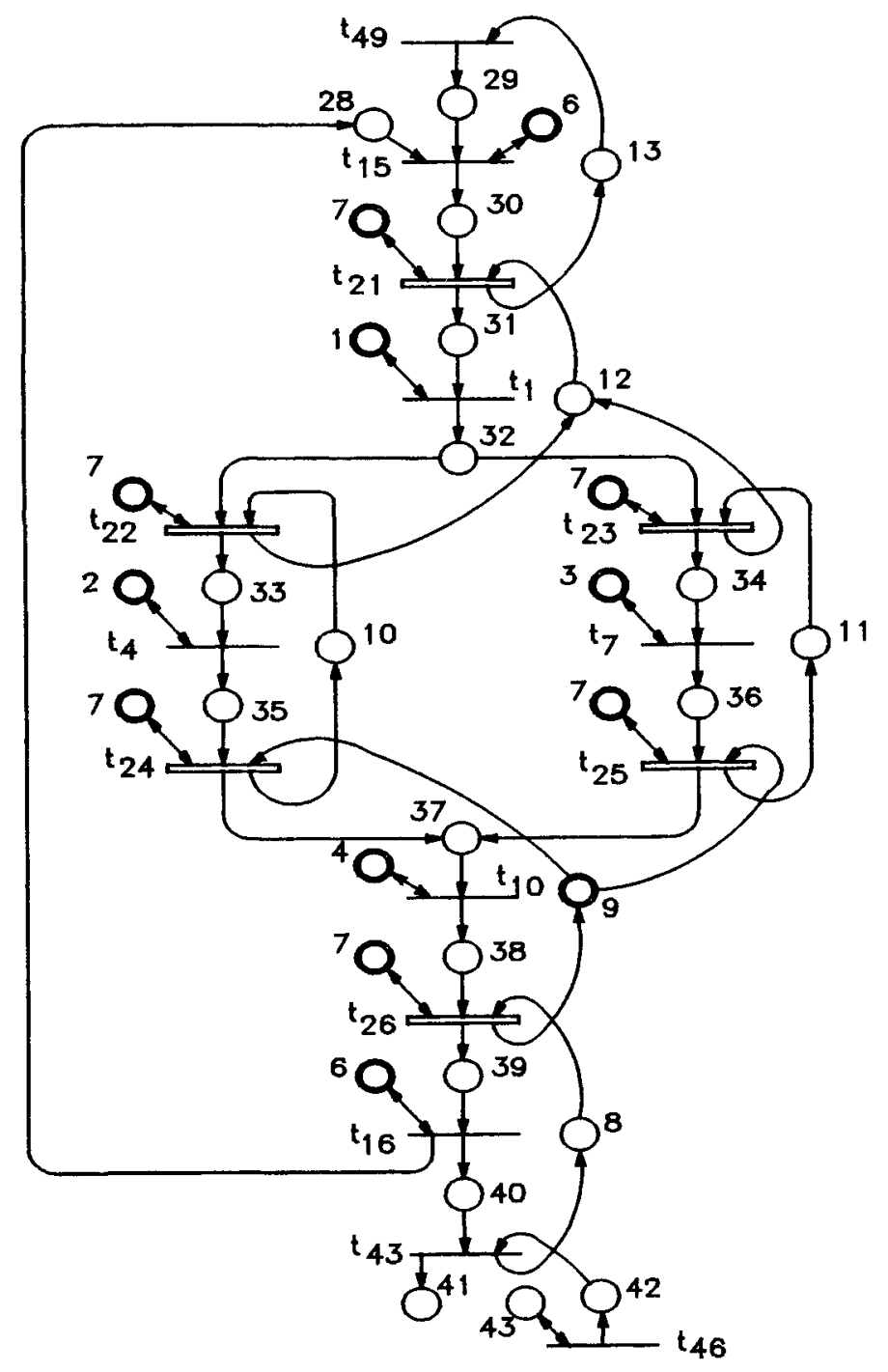

Figure 4. Priority net model for part type 1.

receive more than one component. In one publication (Gentili 1991), it is reported that FMS equipped with multi-piece adaptable pallets is able to work satisfactorily in JIT environment.

3.4b Number of kanbans: If there are more part types in the system at a time, the total inventory in the system will be very high. This is because the inventories have to be maintained at all stages for all part types for implementing the pull mechanism. This problem can be overcome by freezing schedules for a small period of time (a week or 10 days), which helps in keeping the variables low, and also continuing the same part-mix throughout that period. 


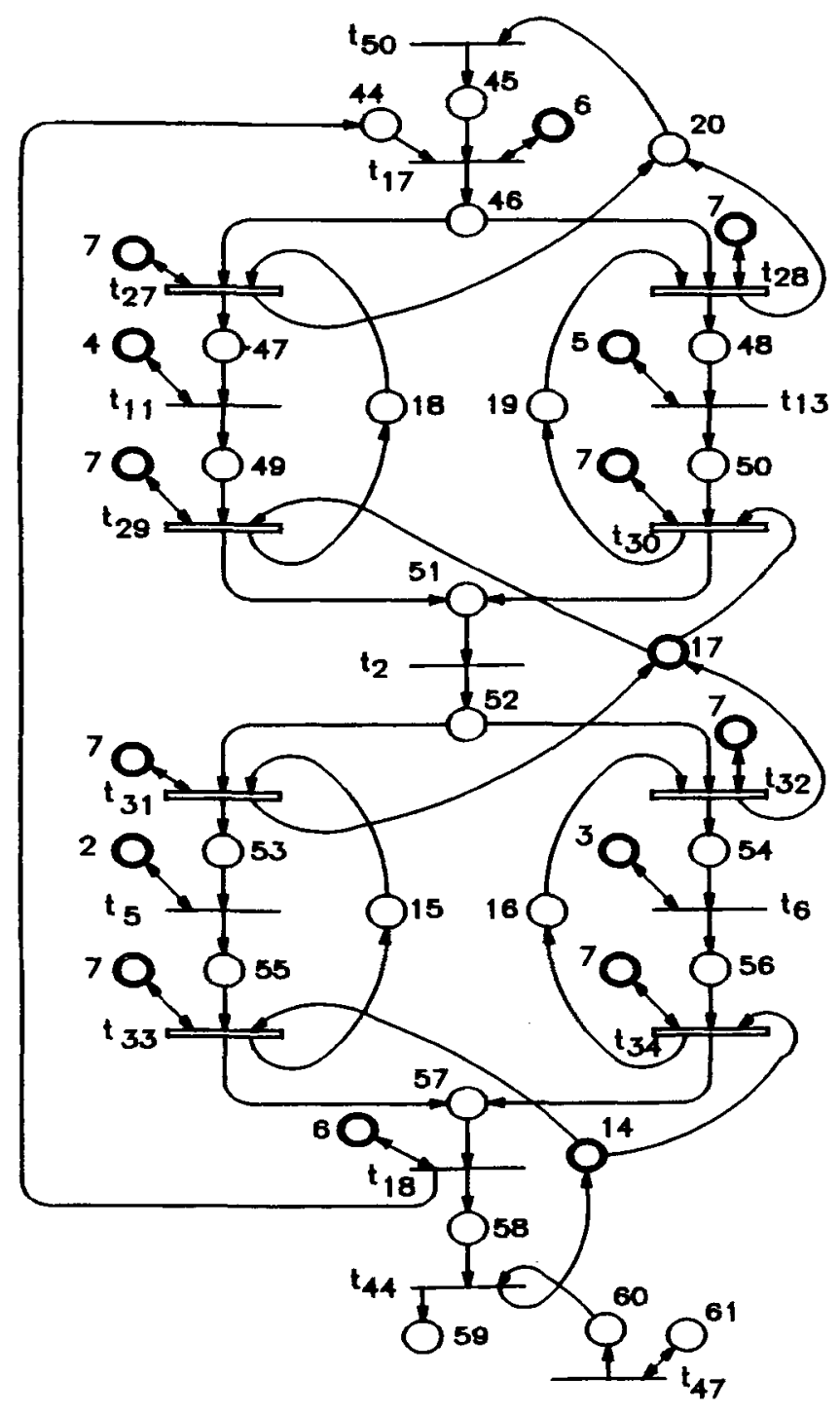

Figure 5. Priority net model for part type 2.

Part type changes - Whenever a new part type enters the system, its routing and the number of kanbans have to be carefully determined. Then the 'start up' for the part type (i.e. generation of kanbans on the computers, passing the kanban information to the respective machining centres etc.) has to be planned. Similarly, whenever a part type goes out of the system, its 'cut off' has to be planned to gradually remove the inventories (kanbans) associated with the part type.

Volume changes - Even though the part mix is stable over a period of time, individual demand may vary significantly in some systems. In such cases, the system will not be able to operate in equilibrium with a fixed number of kanbans. The number of kanbans has to be dynamically adjusted based on forecasts of demand and demand variability. 


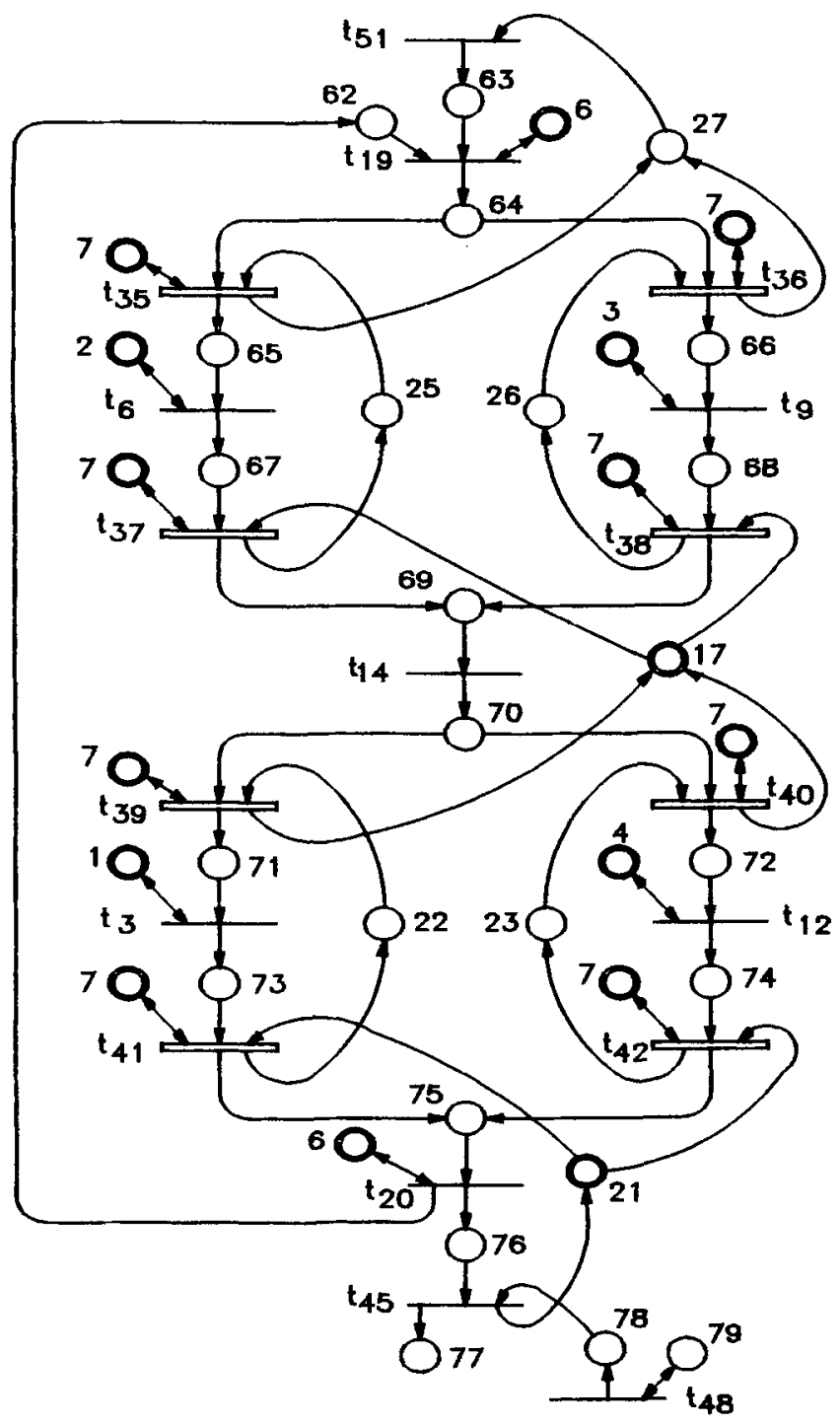

Figure 6. Priority net model for part type 3.

\subsection{Part routings and layout}

FMSs offer flexible routing to the parts. However, simpler routings are advantageous in implementation of JIT. Adoption of Virtual Cell Manufacturing (VCM) principles and layouts is helpful for implementing JIT in flexible manufacturing environments. VCM is a new concept in small batch manufacturing (Drolet et al 1990). A VCM system does not promote opportunistic re-routing of each part after each operation like FMS. Instead, the route of a job (or a set of similar parts) is defined at a virtual cell. Whenever a new part type enters the system a new virtual cell is created. Drolet et al (1991), demonstrated that 'the VCM layout concept will function in harmony with JIT'. 
Table 3. Interpretation of places.

\begin{tabular}{llcl}
\hline Place & \multicolumn{1}{c}{ Interpretation } & Place & \multicolumn{1}{c}{ Interpretation } \\
\hline 1 & M1 free & 54 & PR2 in M3's input buffer \\
2 & M2 free & 55 & PR2 in M2's output buffer \\
3 & M3 free & 56 & PR2 in M3's output buffer \\
4 & M4 free & 57 & PR2 at LUS after processing \\
5 & M5 free & 58 & Finished part of PR2 available at LUS \\
6 & LUS free & 59 & Counter for PR2 \\
7 & AGV available & 60 & Demand for PR2 \\
$8-13$ & C-kanban post PR1 in kanban post & 61 & Place for modelling different \\
$14-20$ & C-kanban post for PR2 in kanban post & & demand patterns of PR2 \\
$21-27$ & C-kanban post for PR3 in kanban post & 62 & Fixtures for PR3 available \\
28 & Fixtures for PR1 available & 63 & Raw material for PR3 available at LUS \\
29 & Raw material for PR1 available & 64 & Loaded pallet for PR3 available at LUS \\
30 & Loaded pallet for PR1 available at LUS & 65 & PR3 in M2's input buffer \\
31 & PR1 in M1's input buffer & 66 & PR3 in M3's input buffer \\
32 & PR1 in M1's output buffer & 67 & PR3 in M2's output buffer \\
33 & PR1 in M2's input buffer & 68 & PR3 in M3's output buffer \\
34 & PR1 in M3's input buffer & 69 & PR3 in M5's input buffer \\
35 & PR1 in M2's output buffer & 70 & PR3 in M5's output buffer \\
36 & PR1 in M3's output buffer & 71 & PR3 in M1's input buffer \\
37 & PR1 in M4's input buffer & 72 & PR3 in M4's input buffer \\
38 & PR1 in M4's output buffer & 73 & PR3 in M1's output buffer \\
39 & PR1 at LUS after processing & 74 & PR3 in M4's output buffer \\
40 & Finished part of PR1 available at LUS & 75 & PR3 at LUS after processing \\
41 & Counter for PR1 & 76 & Finished part of PR3 available at LUS \\
42 & Demand for PR1 & 77 & Counter for PR3 \\
51 & PR2 in M1's input buffer & 78 & Demand for PR3 \\
52 & PR2 in M1's output buffer & 79 & Place for modeling different \\
53 & PR2 in M2's input buffer & & demand patterns of PR3 \\
\hline & & &
\end{tabular}

\subsection{AGV related issues}

These are mainly, (i) the determination of number of AGVs, and (ii) dispatching. Some of the traditional dispatching rules used in push systems may not be suitable in JIT environments. In the present work, some of the implementation issues such as number of kanbans, kanban sizes and vehicle dispatching are addressed with the help of Priority nets.

\section{Modelling and simulation of FMS}

Modelling and analysis of FMSs implementing a pull mechanism are highly complex due to the multiple part types and AGV-based transportation environment. Priority nets can be effectively used to address these issues. To demonstrate the efficacy of PRNs for modelling pull mechanism in FMSs, a system with the following features is considered.

- The layout of the system is shown in figure 3. The system consists of five machining centres and a load-unload station connected by AGV network. It caters to a variety of part types. Three part types are considered for the present study. The machining sequences and processing times are indicated in table 1. 
Table 4. Interpretation of transitions.

\begin{tabular}{llcl}
\hline Transition & \multicolumn{1}{c}{ Interpretation } & Transition & \multicolumn{1}{c}{ Interpretation } \\
\hline 1 & M1 processing PR1 & 25 & Transportation of PR1, M3 to M4 \\
2 & M1 processing PR2 & 26 & Transportation of PR1, M4 to LUS \\
3 & M1 processing PR3 & 27 & Transportation of PR2, LUS to M4 \\
4 & M2 processing PR1 & 28 & Transportation of PR2, LUS to M5 \\
5 & M2 processing PR2 & 29 & Transportation of PR2, M4 to M1 \\
6 & M2 processing PR3 & 30 & Transportation of PR2, M5 to M1 \\
7 & M3 processing PR1 & 31 & Transportation of PR2, M1 to M2 \\
8 & M3 processing PR2 & 32 & Transportation of PR2, M1 to M3 \\
9 & M3 processing PR3 & 33 & Transportation of PR2, M2 to LUS \\
10 & M4 processing PR1 & 34 & Transportation of PR2, M3 to LUS \\
11 & M4 processing PR2 & 35 & Transportation of PR3, LUS to M2 \\
12 & M4 processing PR3 & 36 & Transportation of PR3, LUS to M3 \\
13 & M5 processing PR2 & 37 & Transportation of PR3, M3 to M5 \\
14 & M5 processing PR3 & 38 & Transportation of PR3, M3 to M5 \\
15 & Loading PR1 on pallet & 39 & Transportation of PR3, M5 to M1 \\
16 & Unloading PR1 from the pallet & 40 & Transportation of PR3, M5 to M4 \\
17 & Loading PR2 on pallet & 41 & Transportation of PR3, M1 to LUS \\
18 & Unloading PR2 from the pallet & 42 & Transportation of PR3, M4 to LUS \\
19 & Loading PR3 on pallet & 43 & Consumption of finished part of PR1 \\
20 & Unloading PR3 from the pallet & 44 & Consumption of finished part of PR2 \\
21 & Transportation of PR1, LUS to M1 & 45 & Consumption of finished part of PR3 \\
22 & Transportation of PR1, M1 to M2 & 46 & Arrival of demand for PR1 \\
23 & Transportation of PR1, M1 to M3 & 47 & Arrival of demand for PR2 \\
24 & Transportation of PR1, M2 to M4 & 48 & Arrival of demand for PR3 \\
\hline
\end{tabular}

- The AGV track layout consists of both uni-directional and bi-directional segments. Control points are provided on the layout to avoid vehicle collisions. Bi-directional AGVs are used in the system. AGVs, when unassigned, wait in the charging stations provided on the track.

- The system uses only conveyance kanbans (C-kanbans) for implementing pull mechanism.

The following assumptions are made:

(1) An AGV takes 30 seconds for loading/unloading and 5 seconds to cross a control point. The time required to cover different segments is given in table 2 .

(2) Raw materials are available in perennial supply.

\subsection{Modelling}

A hierarchical modelling methodology is adopted. At the higher level the pull mechanism is modelled. This is referred to as system net. At the lower level the AGVS is modelled, which is referred to as logistic net. For the system net a part variety based approach is adopted. The PRN model of pull mechanism of each part type is made separately. These PRNM are then linked by merging the common D-places to yield the system net. The PRNMs of each part type is shown in figures 4 to 6 . The interpretations of places and transitions are given in tables 3 and 4 respectively. The logistic net of the system is shown in figure 7, details are given in Ravi Raju \& Chetty (1993). 


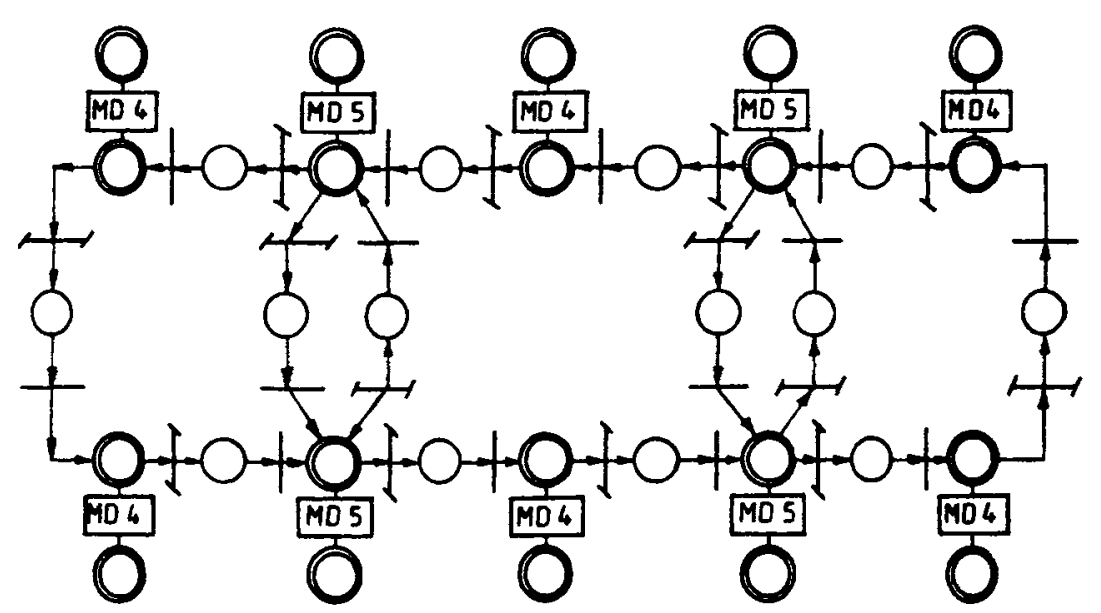

Figure 7. Logistic net of the system.

\subsection{Simulation}

The system is simulated by the concurrent execution of the system net and logistic net. Control strategies are implemented with the help of D-places. D-places associated with machines resolve conflicts among transitions representing processing activities. D-places associated with AGVs resolve conflicts among transitions representing transportation activities.

AGV movements are simulated by the logistic net, figure 7 . Whenever an unload transition in the logistic net fires, it changes the attribute AGV engaged to zero, and thus terminates the firing of a transition representing a transportation activity in the system net. An Ada-based software package JIT-SIM is developed for the simulation of JIT systems. The basic inputs to the package include system net details and AGVS details. The interactive input to the package includes a number of AGVs and their locations, number of kanbans at each stage, kanban sizes, variability in the processing times, job selection rules, machine selection rules, and simulation time. In addition to the usual information, the JIT-SIM gives the important performance measures relevant to the JIT environment, such as percentage of back-ordered demand, mean tardiness, average in-process inventory, cumulative machine idle time, and overtime.

Table 5. Inter-arrival times.

\begin{tabular}{lcl}
\hline Part type & Mean arrival time & \multicolumn{1}{c}{ Inter-arrival times (min) } \\
PR1 & 10 & 022181422201748818297102411332561624145 \\
& 12 & 12017524151800162101827039516012459 \\
PR2 & 9211093915112812163118106227921232540030 \\
PR3 & 15 & $\begin{array}{l}401271316005435 \\
\end{array}$ \\
\hline
\end{tabular}




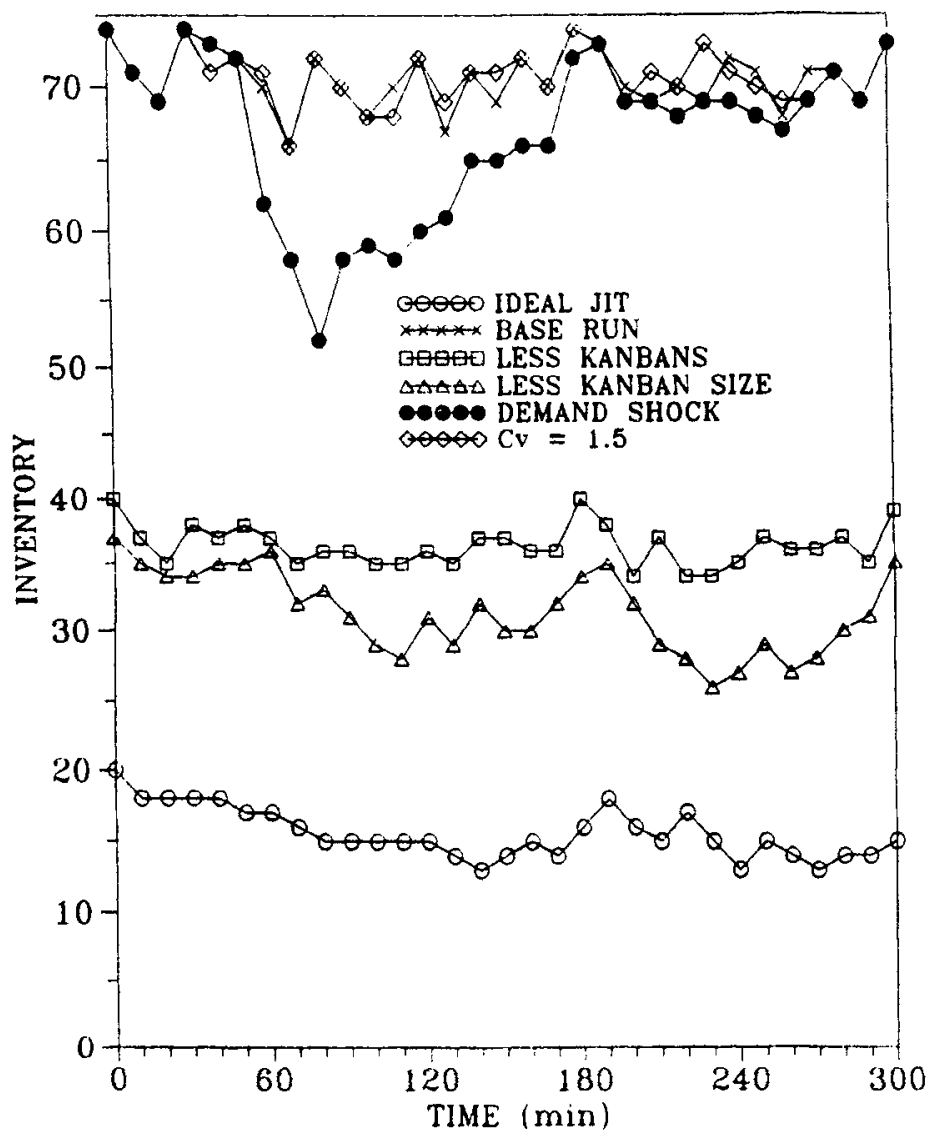

Figure 8. Variation of in-process inventory.

\section{Analysis}

The following design issues are addressed in the present study:

- Number of kanbans

- Kanban size

- Vehicle dispatching

Being a demand-driven system, the functioning of a JIT system starts with the arrival of a demand. A Poisson arrival pattern with a different mean arrival time for each part variety is considered in the present study. Inter-arrival times for each part type are shown in table 5. The same inter-arrival times are used in all simulation experiments in order to investigate the effects of different variables on system performance. In the initial analysis phase, several simulation runs are conducted to probe into the behaviour of the system. Some important experiments are identified and their description and results are discussed below. 


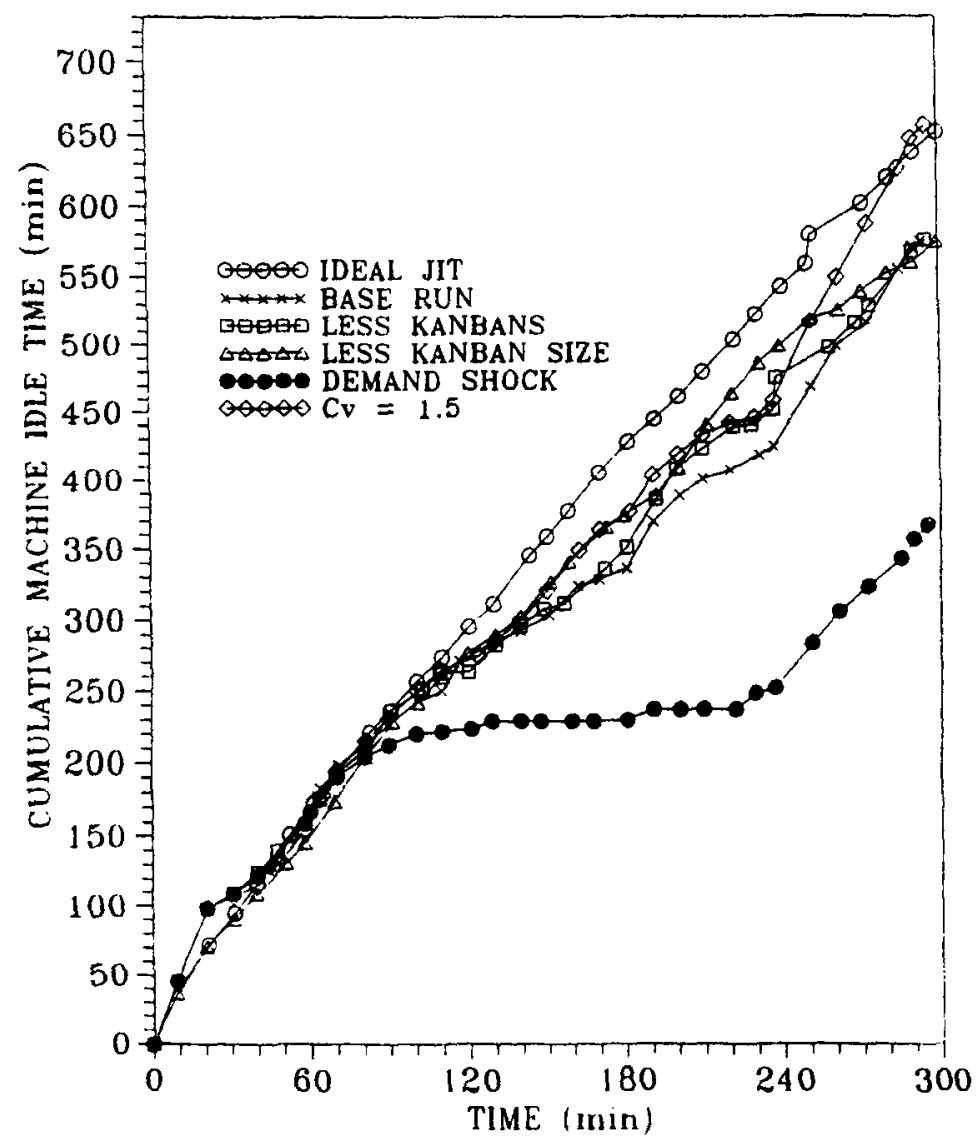

Figure 9. Variation of machine idle time.

(1) Base run: The purpose of the base run is to examine the model under typical conditions which will then serve as the basis for comparison in other experiments. The following parameter settings are used for this experiment.

(i) Number of $\mathrm{AGVs}=3$.

(ii) Number of kanbans $=2$.

(iii) Kanban size $=2$.

(iv) No variation in processing times.

In all the other runs that follow, the parameters are compared with those of the base run.

(2) Run one (less kanban size): The purpose of this run is to evaluate the effect of reduced lot size. The same settings are maintained as in base run except that the size of the kanban is reduced to one.

(3) Run two (less kanbans): In this experiment the effect of number of kanbans is investigated. With the original value of kanban size the number of kanbans is reduced to one. 


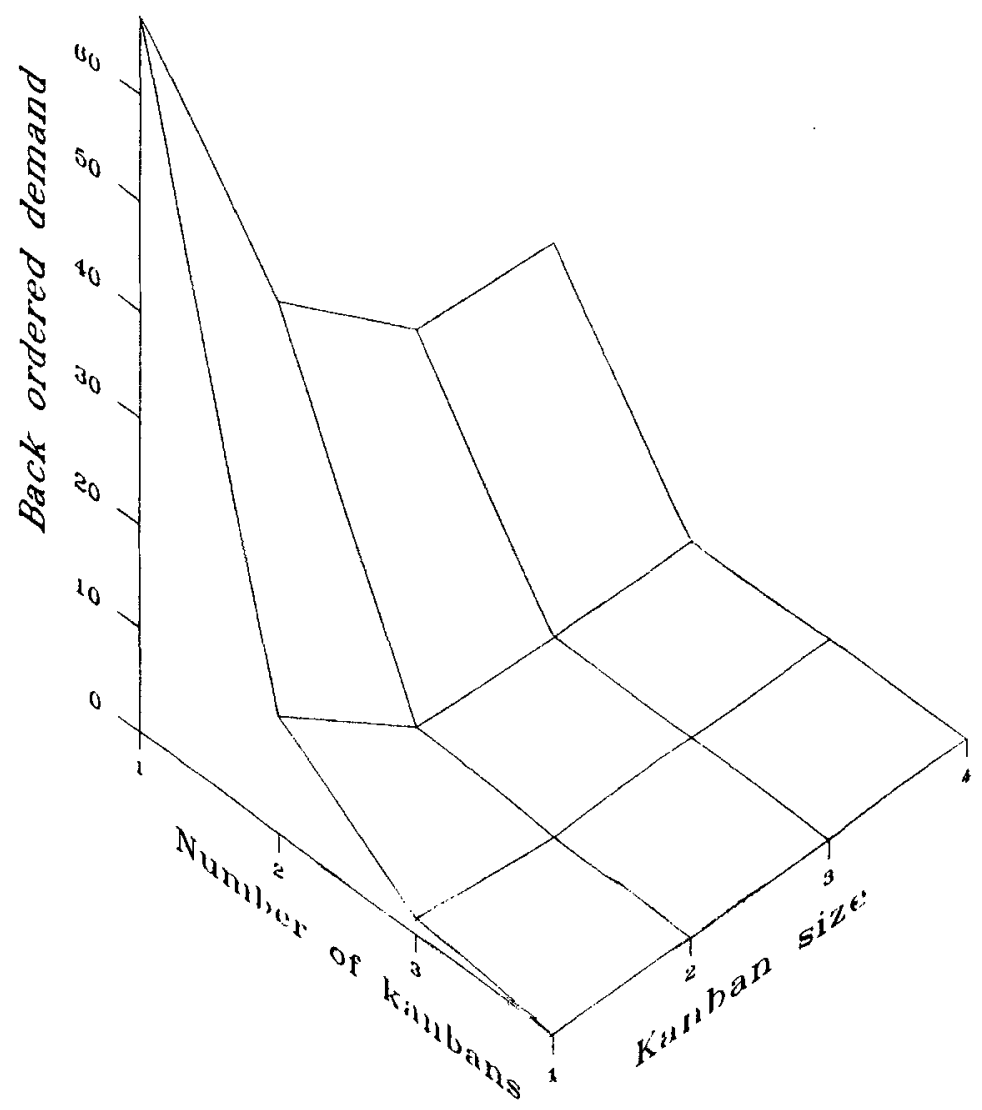

Figure 10. Variation of back ordered demand.

The intent of this test is to provide a contrast to the previous experiment (run one) and evaluate both the methods of reducing work in process inventory.

(4) Run three (demand shock): The purpose of this study is to evaluate the sensitivity of the system to demand shock. A demand shock ( 6 products of each part variety) is introduced at the beginning of the second hour. A JIT system, to be efficient, should support significant demand shocks for a short period of time.

(5) Run four $(C v=1.5)$ : The purpose of this run is to evaluate the effects of variability in processing times. All parameters of this run are same as that of the base run, except that there is $50 \%$ variability in processing times.

(6) Run five (ideal JIT): In this final experiment the system is evaluated with the smallest possible work-in-process level. This is accomplished with the following:

(i) Number of kanbans $=1$.

(ii) Kanban size $=1$. 


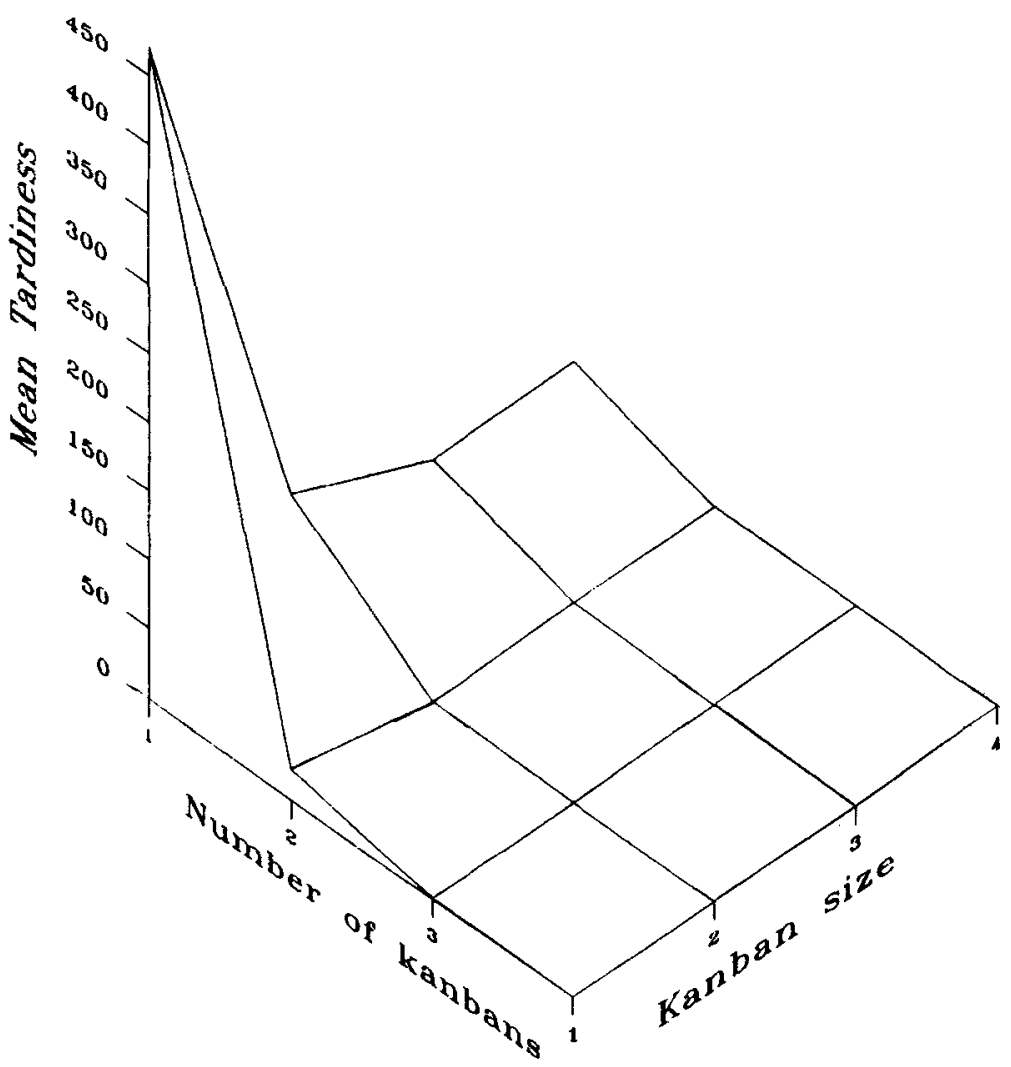

Figure 11. Variation of mean tardiness.

All the above simulation runs are compared with the help of two important performance measures namely in-process inventory and cumulative machine idle time. Figure 8 shows the comparison with respect to in-process inventory. Experiments with low kanbans and a kanban size of two (base run, run 3, run 4) have higher inventory levels. Runs with smaller kanban size and fewer kanbans (runs 1 and 2) have reduced inventory levels. Run 5 (ideal JIT) has minimum inventory and is as expected. An important feature of inventory can be observed in run 3 , where there is a rapid decline of inventory during the second hour. This is due to the demand shock which comes into effect during this period and depletes the inventory. The comparison of runs 1 and 2 suggests that it is more effective to have a large number of kanbans with small size instead of a fewer kanbans with large capacity.

The other comparison is made with respect to cumulative machine idle time, figure 9 . It is found to increase as the inventory reduces. The idle for the third experiment (demand shock) is minimum. Also, idle time remains unchanged during second and third hours. This is due to the fact that machines are kept busy during this period due to demand shock. It is found that idle time increases steeply in all other cases. This may be due to the fact that machines are kept busy during this period due to demand shock. It is found that idle time increases steeply in all other cases. This may be due to lower consumption rates and 


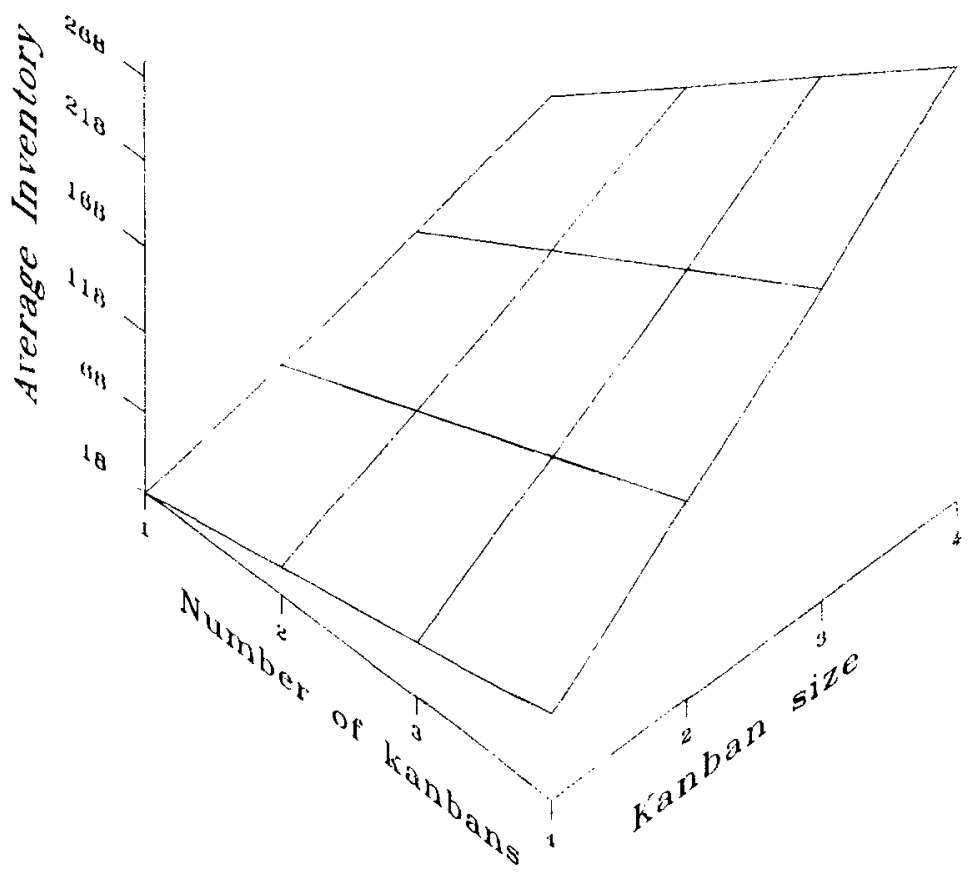

Figure 12. Variation of average inventory.

reduced number of AGVs. Another important finding is that the variability in processing times (run 4) results in increases in machine idle time.

Number of kanbans and kanban size: The three parameters considered for this analysis are percentage of back-ordered demand, mean tardiness and average in-process inventory. Three-dimensional plots in figures 10 to 12 show the effects of the number of kanbans and kanban size. As the number of kanbans increases, the percentage of back-ordered demand falls sharply at the beginning and reaches a minimum value. The same trend is observed with respect to kanban size.

Figure 11 shows the variation of mean tardiness. This varies in a similar fashion as in the case of back-ordered demand. Figure 12 shows that the in-process inventory increases sharply with increase in the number of kanbans and kanban size. Therefore, considering the in-process inventory, mean tardiness, mean back-ordered demand, two kanbans at every

Table 6. Effect of number of kanbans and kanban size.

\begin{tabular}{|c|c|c|c|c|c|c|c|}
\hline \multirow{2}{*}{$\begin{array}{l}\text { Number of } \\
\text { kanbans }\end{array}$} & \multirow{2}{*}{$\begin{array}{l}\text { Kanban } \\
\text { size }\end{array}$} & \multicolumn{3}{|c|}{ Day's schedule } & \multirow{2}{*}{$\begin{array}{l}\text { Completion } \\
\text { time (s) }\end{array}$} & \multirow[t]{2}{*}{$\mathrm{AMU}^{*}$} & \multirow[t]{2}{*}{ AVU } \\
\hline & & PR1 & PR2 & PR3 & & & \\
\hline 2 & 1 & 54 & 37 & 36 & 23545 & 74.6 & 93.0 \\
\hline 1 & 2 & 54 & 37 & 36 & 22953 & 76.2 & 51.9 \\
\hline 2 & 1 & 40 & 40 & 40 & 21951 & 76.5 & 93.4 \\
\hline 1 & 2 & 40 & 40 & 40 & 20724 & 83.2 & 57.4 \\
\hline
\end{tabular}

AMU - Average Machine Utilization; AVU - Average Vehicle Utilization 
Table 7. Effect of redundant work dispatching rules.

\begin{tabular}{lcccc}
\hline $\begin{array}{l}\text { Redundant work } \\
\text { dispatching rule }\end{array}$ & $\begin{array}{c}\text { Cumulative machine } \\
\text { idle time }(\mathrm{min})\end{array}$ & $\begin{array}{c}\text { Back ordered } \\
\text { demand }(\%)\end{array}$ & $\begin{array}{c}\text { Mean tardiness } \\
(\mathrm{s})\end{array}$ & $\begin{array}{c}\text { Average vehicle } \\
\text { utilization }(\%)\end{array}$ \\
\hline ED & 111.98 & 69.29 & 828.6 & 83.36 \\
STT & 105.98 & 66.92 & 463.3 & 80.15 \\
MSPT & 110.95 & 70.86 & 795.3 & 81.50 \\
RJ & 111.80 & 70.07 & 828.7 & 82.87 \\
\hline
\end{tabular}

Job selection rule: SPT; Machine selection rule: LUM; Redundant vehicle dispatching rule: LUV

stage for each part variety, with size of kanban being ' 1 ', are found suitable for the system under study.

The analysis of the same system working to a daily schedule (single kanban) is also considered. In this case, the system acts as a push system for production and pull system for replenishments. Some typical results are shown in table 6. A kanban size of two with a single kanban at each stage is found to yield better results in this case.

Vehicle dispatching: The following dispatching rules are considered for the present study. Redundant work dispatching rules:

(1) Earliest Demand (ED);

(2) Shortest Travel Time (STT);

(3) Minimum work in queue (MWQ);

(4) Random Job (RJ).

Redundant Vehicle dispatching rules:

(1) Least Utilized Vehicle (LUV);

(2) Nearest Idle Vehicle (NIV);

(3) Longest Idle Vehicle (LIV);

(4) Random Vehicle (RV).

Table 7 show's the effect of redundant work dispatching rules. STT is found to give better results with respect to vehicle utilization and other performance measures noted in this table. Table 8 shows the effect of redundant vehicle dispatching rules. LIV is found to perform well with respect to tardiness and back ordered demand. NIV is found to give better result with respect to minimum vehicle movement.

Table 8. Effect of redundant vehicle dispatching rules.

\begin{tabular}{lcccc}
\hline $\begin{array}{l}\text { Redundant vehicle } \\
\text { dispatching rule }\end{array}$ & $\begin{array}{c}\text { Cumulative } \\
\text { machine idle time } \\
(\min )\end{array}$ & $\begin{array}{c}\text { Back-ordered } \\
\text { demand }(\%)\end{array}$ & $\begin{array}{c}\text { Mean tardiness } \\
(\mathrm{s})\end{array}$ & $\begin{array}{c}\text { Average vehicle } \\
\text { utilization }(\%)\end{array}$ \\
\hline LUV & 105.98 & 66.92 & 463.3 & 80.15 \\
NIV & 106.79 & 67.17 & 470.3 & 78.35 \\
LIV & 107.17 & 64.57 & 354.8 & 79.49 \\
RV & 109.32 & 67.71 & 675.5 & 79.48 \\
\hline
\end{tabular}

Job selection rule: SPT; Machine selection rule: LUM; Redundant work dispatching rule: STT 


\section{Conciusion}

In this paper, an attempt is made to address the modelling, simulation and implementation issues of JIT in flexible manufacturing environment. Priority nets are proved to be suitable and competent tools for the modelling and analysis of kanban systems. Realizing the need for a thorough investigation of JIT in FMSs, an FMS implementing pull strategy is modelled. A large number of simulation runs are conducted to probe the behaviour of the system with respect to different parameter changes such as variability in processing times, demand shock, kanban size and number of kanbans. Implementation issues such as number of kanbans, kanban size, vehicle dispatching etc.. are effectively addressed with the help of priority nets, thereby proving their utility.

\section{References}

Bitran G R, Chang L 1987 A mathematical programming approach to a deterministic kanban system. Manage. Sci. 33: 427-441

Drolet J, Montreuil B, Moodie R, Colin L 1990 Virtual cellular manufacturing layout planning. Proc. of Industrial Engineering Conference, San Francisco, California, pp 236-241

Drolet J, Montreuil B, Moodie C L 199 I Empirical investigation of virtual cellular manufacturing systems. Proc. of International Conference on Computer Integrated Manufacturing. Singapore. pp 323-326

Gentili E 1991 Flexibility and JIT: A new advantage for FMS. Proc. of International Conference on Computer Integrated Manufacturing, Singapore. pp 311-314

Gravel M, Price L W 1988 Using the kanban in a job shop environment. Int. J. Prod. Res. 26: $1105-1118$

Gupta P Y, Gupta M 1989 A system dynamics model of a JIT-Kanban system. Eng. Costs Prod. Econ. 18: 117-130

Huang P Y, Rees L P, Tylor B W 1983 A simulation analysis of Japanese Just-In-Time technique (with kanbans) for a multiline, multistage production system. Decision Sci. 14: 326-344

Kim G C, Schniederjans M J 1990 A high performance programmable controller for CIM systems based on Petri net theory. Proc: of IECON 89, 15th Annual Conference of IEEE Industrial Electronics Society, Philadelphia. pp 805-810

Lulu M. Black J T 1987 Effect of process unreliability on integrated manufacturing/production systems. J. Manuf. Syst. 3: 189-211

Mascolo M D, Frein Y. Dallery Y, David R 1991 A unified modelling of Kanban systems using Petri nets. Int. J. Flexible Manuf. Syst. 3: 275-307

Masuyama A 1986 Idea and practice of flexible manufacturing system at Toyota. Applying JustIn-Time (ed.) Y Monden (Industrial Engineering and Management Press)

Mitra D, Mitrani I 1988 Analysis of a novel discipline for cell coordination in production lines. Technical report, AT\&T Laboratories, NJ

Monden Y 1981 How Toyota shortened supply lot production time, waiting time, and conveyance time. Ind. Eng. 13: 22-29

Monden Y 1983 Toyota production system (Institute of Industrial Engineering: Industrial Engineering and Management Press)

Narendar K R, Mehra S, Frolick M N 1995 A comparative analysis and review of JIT 'implementation' research. Int. J. Oper. Manage. 15: 8-18 
Ravi Raju K, Chetty O V K 1993 Priority nets for scheduling flexible manufacturing systems. $J$. Manuf. Syst. 12: 326-340

Schonberger R J 1982 Japanese manufacturing techniques (New York: Free Press)

Schroer B J, Black J T, Zhang S X 1985 Just-In-Time (JIT) with Kanban, manufacturing system simulation on a microcomputer. Simulation $45: 62-70$

Sugimori Y, Kusunoki K, Cho F, Uchikawa S 1977 Toyota production system and kanban system materialization of Just-In-Time and Respect-for-Human system. Int. J. Prod. Res. 15: 553-564

Talavase J, Hannam R G 1988 Flexible manufacturing systems in practice: Applications, design and simulation (New York: Marcel Dekker)

Voss C A, Harrison A 1987 Strategies for implementing JIT. Proc. of 4th European Conference on Automated Manufacturing, Birmingham, pp 57-73

Wang H, Wang H P 1991 Optimum number of kanbans between two adjacent workstations in a JIT system. Int. J. Prod. Econ. 22: 179-188

White R E 1993 An empirical assessment of JIT in US manufacturers. Prod. Inventory Manage. J. $34: 38-42$

Wilson I B 1986 Achieving flexibility in assembly through technology and people. Proc. of 7th Int. Conference of assembly automation, Zurich, pp 191-202 